description, but the final chapter on primary cells and accumulators is a happier combination of both practical and academic points of view. It includes sound summaries on fuel-cells and recent improvements to alkaline accumulators such as the silver-zinc type.

Although Electrochemical Reactions is described as being written for analytical chemists it is biased rather more towards theoretical aspects than towards practical considerations. There are no specific accounts of instrumentation nor detailed accounts of analytical methods. The topics covered are potentiometry, polarography and associated methods such as amperometry, electrolytic separations and coulometry. In general, the approach has been to discuss all possible types of reactions and then to illustrate each type by examples. No stone seems to be left unturned in this respect, but while the treatment is most competent, one gets the impression of far too much subdivision. As an example of this, the theory of electrolysis is discussed in terms of current-potential curves when: $(a)$ a reducing or oxidizing agent is present; (b) when these belong to the same redox system; (c) when several such systems are present; $(d)$ when two electrodes are present-separated by a membrane-identical electrodes-different electrodes; $(e)$ when the solvent reacts; $(f)$ when transference occurs by migration, diffusion, convection. These are illustrated by idealized currentpotential diagrams as is most of the book to the tune of some four hundred figures.

In spite of this rather tedious manner of presentation, the contents will be most useful to practising analysts who are concerned with research and development problems and those who wish to keep abreast of recent techniques in these subjects. For example, 'chronoamperometry', that is, polarography at fixed current or potential, following current or potential variations with time is dealt with. Large solid electrodes can be used so that bigger effects are obtained than by the conventional dropping mercury electrode. Other recent trends that are reviewed are studies of electrolysis, potentiometry, etc., in mixed or non-aqueous solvents.

C. B. Monk

\section{VON KÁRMÁN'S LAST LECTURES}

From Low-speed Aerodynamics to Astronautics By Prof. Theodore von Kármán. Co-ordinating Editor: Dr. Shih I. Pai. (International Series of Monographs in Aeronautics and Astronauties.) Pp. xv +82 . (London and New York: Pergamon Press, 1963.) 25s.

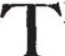
HEODORE voN KÁRMÁN, who died on May 7, 1963 , at the age of eighty-one, was recognized as one of the greatest of aerodynamicists; but no less remarkable was the vigour with which he pursued fresh interests in the last years of his life and encouraged organizations dealing with the new subjects then developing. Born in Budapest, he spent nearly twenty years as director of the Aeronautical Institute at the University of Aachen, before going to the California Institute of Technology in 1930. Although he did not become a United States citizen until he was fifty-five, he had the honour of being the first recipient of the United States National Medal for Science, in 1963.

The title of this little book, From Low-speed Aerodynamics to Astronautics, is in itself a summary of his career, and the text (which is the record of three lectures given in 1961) reflects the development of his interests, from his postgraduate studies at Göttingen in the early years of the century, when Lanchester came to discuss wing theory with Prandtl, to the 1960 's, when von Kármán founded the International Academy of Astronautics. The first of the three main sections of the book, entitled "Aerothermodynamies", is a concise survey of aerody. namies from incompressible flow to hypersonics. Tho second main subject, "Aerothermochemistry", covering flow problems in which chemical reactions occur, is concerned mainly with re-entry into the atmosphere from near-orbital speeds. Finally, after a brief and rather unsatisfactory note on "Rarefied Gasdynamies", comes an introduction to "Magneto-fluid-dynamics", in which the chief phenomena are outlined and the important nondimensional parameters are defined.

Prof. von Kármán's review articles are famous for going to the heart of the matter with the minimum of fuss, and bringing out the essential physical principles with simple mathematics. These qualities are again evident here, and the section on aerothermodynamics is particularly rewarding. The text is built round the numerous and informative diagrams, which are taken largely from specialized papers: this is an excellent plan, but its execution is sometimes marred by inadequate captions to the diagrams (and rather too rich a crop of misprints). The style is informal and economical, with plenty of witty asides: for example, we are told that at least three German professors named Schmidt each thought that the "Schmidt number" was in honour of himself.

The book is a most useful introduction to the wide range of topies it covers. But it is also a contribution to the history of the subject, and an epitome of the unique career of a man who stood in the main stream of development in aerodynamics and aerospace engineering, and wisely guided that stream on its way to ever higher Mach numbers.

D. G. KING-HeLE

\section{ASPHALT: SCIENCE AND TECHNOLOGY}

\section{Asphalt Science and Technology}

A Comprehensive One-volume Survey, Encyclopedic in Scope, correlating the Physics, Chemistry and Rheology of Petroloum and Synthetic Asphalts with an Authoritative and Detailed Presentation of Modern Asphalt Manufacturing and Test Methods for a Wide Range of Asphalt End-uses. By Edwin J. Barth. Pp. xx+700. (New York: Gordon and Breach Science Publishers, Inc., 1962.) 32.50 dollars.

A SPHALT Science and Technology sets out to provide $A$ "the first truly encyclopedic authoritative coverage of modern petroleum and synthetic asphalts", and does, in fact, contain a large amount of information relating to the classification, chemistry and physics of asphalts or bitumens. The use of these materials in work such as road surfacing is also discussed at some length, with particular reference to such factors as durability.

Having regard to the origin of this book, it naturally makes use of nomenclature which is, in certain respects, different from that now in use among asphalt technologists in Britain, and it is, for example, somewhat disconcerting to find petroleum refinery bitumens classified as 'artificial asphalts'. Again the British reader may shy at words such as 'voluminosity', but the technologist will have no serious difficulty.

Much of the asphalt technology in Britain has followed very traditional lines, and Edwin $J$. Barth provides a refreshingly new outlook on a considerable number of fundamental problems which should lead to a better understanding of this rather specialist subject. For example, Barth discusses at length the nature and influence of the asphaltenes in bitumens, dealing particularly with the carbon/hydrogen ratio, not only as a basis for classification, but also as an important factor in determining the overall chemical and physical characteristics of a bitumen. The basic idea that bitumens moy be regarded as an oily medium in which are dispersed asphalt micelles or asphaltenes was probably first propounded by Boussingault in 1937. However, it is only in 